\title{
Pretreatment identification of micro-metastasis in mediastinal lymph node by endobronchial ultrasound-guided transbronchial needle aspiration for early-stage non-small cell lung cancer-is it time yet?
}

\author{
Abhishek Biswas ${ }^{1}$, Michael A. Jantz ${ }^{2}$, Hiren J. Mehta ${ }^{2}$ \\ ${ }^{1}$ Director of Interventional Pulmonology, Parkview Regional Medical Center, Fort Wayne, IN, USA; ${ }^{2}$ Division of Pulmonary and Critical Care \\ Medicine, University of Florida, Gainesville, FL, USA \\ Correspondence to: Abhishek Biswas, MD, FACP, FCCP. Director of Interventional Pulmonology, Parkview Regional Medical Center, 11109 Parkview \\ Plaza Dr, Fort Wayne, IN 46845, USA. Email: abhibiswas78@gmail.com. \\ Comment on: Belanger AR, Hollyfield J, Yacovone G, et al. Incidence and clinical relevance of non-small cell lung cancer lymph node micro-metastasis \\ detected by staging endobronchial ultrasound-guided transbronchial needle aspiration. J Thorac Dis 2019;11:3650-8.
}

Submitted Aug 20, 2019. Accepted for publication Sep 12, 2019.

doi: $10.21037 /$ jtd.2019.09.41

View this article at: http://dx.doi.org/10.21037/jtd.2019.09.41

The dissemination of malignancy to the locoregional lymph nodes (LNs) impacts the prognosis for most cancer types. However, routine LN histopathological examination will occasionally miss smaller tumor deposits. A case in point is breast cancer. The likelihood of identifying a small (threecell diameter) metastatic focus of cancer in a regional LN is approximately $1 \%$ for early-stage breast cancer (1). Though similar data is not available for LN metastases in lung cancer, it is plausible that a similar situation exists for mediastinal LNs that are removed during lung resection surgery or sampled using endobronchial ultrasound-guided transbronchial needle aspiration (EBUS-TBNA). The locoregional recurrence rates for treated early-stage cancer appears to be consistently high between $10-20 \%(2-5)$. This problem merits a closer scrutiny.

The term "micrometastasis" (MM) refers to microscopic deposit of malignant cells, less than $2 \mathrm{~mm}$ in diameter, separated from the primary tumor (6). The Union for International Cancer Control (UICC) further redefined single tumor cells or cell clusters measuring $\leq 0.2 \mathrm{~mm}$ in the greatest dimension as "isolated tumor cells" (ITCs) because of their different biological behavior and size and thus differentiating them from MM (7). In other words, $M M$ is defined as clusters of tumor cells between 0.2 and $2 \mathrm{~mm}$ in the greatest dimension. With the availability of newer techniques such as immunohistochemistry (IHC) and reverse transcription polymerase chain reaction (RTPCR), our ability to detect MM in LNs has increased many fold (8). However, despite the solid evidence supporting the inadequacy of current hematoxylin \& eosin (H\&E) staining of LNs $(9,10)$, few, if any, cancer staging systems include the mention of MM. An exception is breast cancer staging in which MM is given the due importance (11).

A thorough review of cancer literature reveals conflicting evidence for the prognostic implications of $M M$ on outcome for most cancers. A reduced three-year diseasefree survival and higher risk of recurrence was noted for LN MM-positive Stage I-II colorectal cancer (12). A study by Liefers et al. (13) supports the impact of LN MM whereas others disagree $(14,15)$. Inconclusive results are available from the literature on the effect of MM on survival in early gastric cancers $(8,16,17)$. With use of IHC, the detection of MM in LNs with gall bladder cancer has been noted to have an impact on survival (18). Other studies suggested a lack of an effect on survival, albeit with a higher risk of recurrence when MM is detected in regional LNs for surgically resectable esophageal cancers $(19,20)$. Again, there is disagreement among experts (21).

A review of lung cancer literature reveals varying detection range for LN MM in mediastinal LNs, ranging between $10.4 \%$ to $80.0 \%$ (22). Differences in detection technique and tissue preparation may account for this 
wide range. Some authors have used different detection techniques and identified variable detection rates on the same LNs (23). The prognostic implication of LN MM varied with the technique used to identify LN MM (23). Martin et al. demonstrated that MM detected by IHC had an effect on prognosis whereas RT-PCR for calretinin did not (23). The work of other authors support this finding (24). IHC carries with it a risk of false-positive results due to cross-reactivity with normal cellular components $(24,25)$. This finding may have clinical implications. For example, Hashimoto et al. could only detect negative prognostic impact when the MM was diagnosed by the mutant allelespecific amplification (MASA) method (24). Despite the lack of a standardized and a uniform approach for the detection of LN MM, evidence exists to support its clinical significance. Multiple studies demonstrate MM as a negative prognostic factor $(9,23,24,26-35)$, although other authors disagree (36-38). Adding credence to the assumption that MM impact prognosis is the finding that the more aggressive the primary tumor subtype is, the higher is the risk of $M M$ in the mediastinal nodes $(39,40)$. One common feature that unifies the abovementioned studies is the observation that these studies recruited patients who underwent surgical resection of the primary lung lesion. There is, however, no reason to believe that outcomes would be any different for those patients undergoing stereotactic body radiation therapy (SBRT). To shed light on the impact of MM on patients not thought to be a surgical candidate, one must first study the feasibility of detecting MM on LN samples obtained by methods other than surgical mediastinal sampling. EBUSTBNA has become the most widely utilized technique used to sample the mediastinum (41). However, no prior study has used IHC for pan-cytokeratin on EBUS-TBNA LN samples to detect MM before Belanger et al. published their current study. The authors collected data retrospectively on EBUS-TBNA done between September 2013 to October 2017. The strength of the study is in its being a realworld study population with patients undergoing EBUSTBNA for nodal sampling based on current guidelines. This study design increases the likelihood of reproducibility of the data when applied to other larger contemporary patient populations. The authors identified patients with no evidence of cancer metastasis by EBUS-TBNA via $\mathrm{H} \& \mathrm{E}$ staining. Once it was confirmed that these patients did not have N2, N3 and extra thoracic metastatic disease and were candidates for curative therapy, their nodes were then checked for MM using IHC for pancytokeratin. Out of the 44-eligible patients, 3 (6.8\%) had MM detected on the sampled nodes. All of these were N2 stations. They further studied the effect of MM on overall survival and progression-free survival. The authors report the positive association between the presence of MM and both overall survival and progression-free survival, both being statistically significant.

The detected rate of MM is much lower than studies that have included surgically resected mediastinal nodes in earlystage lung cancers. The authors attribute the discrepancy to factors such as the effect of a small sample size, possibility of tissue alteration by the effect of the deparaffinization process and possible sampling error. The authors report that the median number of LN stations sampled during the procedure was three stations. It remains unclear if multiple nodes were sampled at each station.

The results of the survival analysis with three patients is less than convincing and clearly points to the need for further studies including larger number of patients with MM. Despite the limited number of patients, the take-home message from this study should be the fact that EBUSTBNA can be used to detect LN MM in conventional $\mathrm{H} \& \mathrm{E}$ stained disease-negative nodes.

There is good data to suggest that MM occurs in a significant number of surgically resected lung cancer patients and there appears to be evidence to suggest that it impacts disease recurrence rates and progressionfree survival. However, no clear studies exist for those undergoing SBRT. There is a lack of data to determine if LN MM would impact overall survival and disease-free survival among those undergoing SBRT. The presence of MM would not explain risk of local recurrence but may explain the risk of regional failure after SBRT. Regional failure, which is defined as disease progression in the mediastinal nodes or hematogenously within the lung, has been strongly linked to overall survival after SBRT (42). These results prompt us to plan for studies to investigate the prognostic impact of LN MM among those treated by SBRT. In addition, this study makes us ponder over some other questions:

* Is IHC (compared to RT-PCR) the ideal way to detect LN MM?

* Should LN samples be routinely tested for MM both for resectable and unresectable cancers?

* Should the presence of MM in LN stations in absence of metastasis on conventional testing alter stage and management?

We feel that mentioning the LN MM status would be 
justified and likely supported by the scientific community once the detection techniques are standardized and the impact of LN MM on lung cancer prognosis can be validated in both early and advanced stage lung cancers.

Overall, this study will hopefully infuse more interest and enthusiasm into investigations to study the effect of $M M$ on treatment outcomes for those with early-stage cancer. The $8^{\text {th }}$ edition lung cancer classification does not recommend mentioning MM status or suggest looking for it (43). There have been suggestions to follow breast cancer classification systems and include the LN MM status in lung cancer staging information (44). The substantial recurrence rate after definitive surgical resection among those patients with early-stage lung cancer patients strongly speaks for the need to identify the factors causing cancer recurrence $(4,5)$. $\mathrm{LN}$ MM may be one of those. It is high time we considered studying it with a more attentive motive.

\section{Acknowledgments}

None.

\section{Footnote}

Conflicts of Interest: The authors have no conflicts of interest to declare.

Ethical Statement: The authors are accountable for all aspects of the work in ensuring that questions related to the accuracy or integrity of any part of the work are appropriately investigated and resolved.

\section{References}

1. Occult axillary lymph-node micrometastases in breast cancer. Lancet 1990;336:434-5.

2. Wink KCJ, van Baardwijk A, Troost EGC, et al. Nodal recurrence after stereotactic body radiotherapy for early stage non-small cell lung cancer: incidence and proposed risk factors. Cancer Treat Rev 2017;56:8-15.

3. Maeda R, Yoshida J, Ishii G, et al. Risk factors for tumor recurrence in patients with early-stage (stage I and II) non-small cell lung cancer: patient selection criteria for adjuvant chemotherapy according to the seventh edition TNM classification. Chest 2011;140:1494-502.

4. Kelsey CR, Marks LB, Hollis D, et al. Local recurrence after surgery for early stage lung cancer: an 11-year experience with 975 patients. Cancer 2009;115:5218-27.
5. Taylor MD, Nagji AS, Bhamidipati CM, et al. Tumor recurrence after complete resection for non-small cell lung cancer. Ann Thorac Surg 2012;93:1813-20; discussion 1820-1.

6. Bjelovic M, Pesko P, Micev M, et al. The significance of lymphonodal micrometastasis in the patients with gastric adenocarcinoma. Acta Chir Iugosl 2005;52:21-4.

7. Lee CM, Park SS, Kim JH. Current status and scope of lymph node micrometastasis in gastric cancer. J Gastric Cancer 2015;15:1-9.

8. Zhou Y, Zhang GJ, Wang J, et al. Current status of lymph node micrometastasis in gastric cancer. Oncotarget 2017;8:51963-9.

9. Chen ZL, Perez S, Holmes EC, et al. Frequency and distribution of occult micrometastases in lymph nodes of patients with non-small-cell lung carcinoma. J Natl Cancer Inst 1993;85:493-8.

10. Kawano R, Hata E, Ikeda S, et al. Micrometastasis to lymph nodes in stage I left lung cancer patients. Ann Thorac Surg 2002;73:1558-62.

11. Giuliano AE, Connolly JL, Edge SB, et al. Breast CancerMajor changes in the American Joint Committee on Cancer eighth edition cancer staging manual. CA Cancer J Clin 2017;67:290-303.

12. Sloothaak DAM, van der Linden RLA, van de Velde CJH, et al. Prognostic implications of occult nodal tumour cells in stage I and II colon cancer: The correlation between micrometastasis and disease recurrence. Eur J Surg Oncol 2017;43:1456-62.

13. Liefers GJ, Cleton-Jansen AM, van de Velde CJ, et al. Micrometastases and survival in stage II colorectal cancer. N Engl J Med 1998;339:223-8.

14. Davies M, Arumugam PJ, Shah VI, et al. The clinical significance of lymph node micrometastasis in stage I and stage II colorectal cancer. Clin Transl Oncol 2008;10:175-9.

15. Jeffers MD, O'Dowd GM, Mulcahy H, et al. The prognostic significance of immunohistochemically detected lymph node micrometastases in colorectal carcinoma. J Pathol 1994;172:183-7.

16. Ishida K, Katsuyama T, Sugiyama A, et al. Immunohistochemical evaluation of lymph node micrometastases from gastric carcinomas. Cancer 1997;79:1069-76.

17. Morgagni P, Saragoni L, Scarpi E, et al. Lymph node micrometastases in early gastric cancer and their impact on prognosis. World J Surg 2003;27:558-61.

18. Sasaki E, Nagino M, Ebata T, et al. 
Immunohistochemically demonstrated lymph node micrometastasis and prognosis in patients with gallbladder carcinoma. Ann Surg 2006;244:99-105.

19. Nakamura T, Ide H, Eguchi R, et al. Clinical implications of lymph node micrometastasis in patients with histologically node-negative ( $\mathrm{pN} 0$ ) esophageal carcinoma. J Surg Oncol 2002;79:224-9.

20. Komukai S, Nishimaki T, Watanabe H, et al. Significance of immunohistochemically demonstrated micrometastases to lymph nodes in esophageal cancer with histologically negative nodes. Surgery 2000;127:40-6.

21. Sato F, Shimada Y, Li Z, et al. Lymph node micrometastasis and prognosis in patients with oesophageal squamous cell carcinoma. Br J Surg 2001;88:426-32.

22. Jiao X, Krasna MJ. Clinical significance of micrometastasis in lung and esophageal cancer: a new paradigm in thoracic oncology. Ann Thorac Surg 2002;74:278-84.

23. Martin LW, D'Cunha J, Wang X, et al. Detection of occult micrometastases in patients with clinical stage I non-smallcell lung cancer: a prospective analysis of mature results of CALGB 9761 (alliance). J Clin Oncol 2016;34:1484-91.

24. Hashimoto T, Kobayashi Y, Ishikawa Y, et al. Prognostic value of genetically diagnosed lymph node micrometastasis in non-small cell lung carcinoma cases. Cancer Res 2000;60:6472-8.

25. Krismann M, Todt B, Schröder J, et al. Low specificity of cytokeratin 19 reverse transcriptase-polymerase chain reaction analyses for detection of hematogenous lung cancer dissemination. J Clin Oncol 1995;13:2769-75.

26. Dobashi K, Sugio K, Osaki T, et al. Micrometastatic P53positive cells in the lymph nodes of non-small-cell lung cancer: prognostic significance. J Thorac Cardiovasc Surg 1997;114:339-46.

27. Salerno CT, Frizelle S, Niehans GA, et al. Detection of occult micrometastases in non-small cell lung carcinoma by reverse transcriptase-polymerase chain reaction. Chest 1998;113:1526-32.

28. Kubuschok B, Passlick B, Izbicki JR, et al. Disseminated tumor cells in lymph nodes as a determinant for survival in surgically resected non-small-cell lung cancer. J Clin Oncol 1999;17:19-24.

29. Maruyama R, Sugio K, Fukuyama Y, et al. Evaluation of p53 alterations in occult lymph node metastases. J Surg Oncol 2000;73:143-7.

30. Ohta Y, Nozawa H, Tanaka Y, et al. Increased vascular endothelial growth factor and vascular endothelial growth factor-c and decreased nm23 expression associated with microdissemination in the lymph nodes in stage I non-small cell lung cancer. J Thorac Cardiovasc Surg. 2000;119:804-13.

31. Ren Y, Zhang L, Xie H, et al. Lymph node micrometastasis prognosticates survival for patients with stage 1 bronchogenic adenocarcinoma. Ann Surg Oncol 2018;25:3812-9.

32. Deng XF, Jiang L, Liu QX, et al. Lymph node micrometastases are associated with disease recurrence and poor survival for early-stage non-small cell lung cancer patients: a meta-analysis. J Cardiothorac Surg 2016;11:28.

33. Jeong JH, Kim NY, Pyo JS. Prognostic roles of lymph node micrometastasis in non-small cell lung cancer. Pathol Res Pract. 2018;214:240-4.

34. Gwóźdź P, Pasieka-Lis M, Kołodziej K, et al. Prognosis of patients with stages I and II non-small cell lung cancer with nodal micrometastases. Ann Thorac Surg 2018;105:1551-7.

35. Rusch VW, Hawes D, Decker PA, et al. Occult metastases in lymph nodes predict survival in resectable non-smallcell lung cancer: report of the ACOSOG Z0040 trial. J Clin Oncol 2011;29:4313-9.

36. Lafuente-Sanchis A, Estors-Guerrero M, Zúñiga Á, et al. Clinical significance of molecular micrometastasis in the sentinel lymph node of early-stage non-small cell lung cancer patients. Am J Clin Oncol 2018. [Epub ahead of print].

37. Marchevsky AM, Gupta R, Kusuanco D, et al. The presence of isolated tumor cells and micrometastases in the intrathoracic lymph nodes of patients with lung cancer is not associated with decreased survival. Hum Pathol 2010;41:1536-43.

38. Rena O, Carsana L, Cristina S, et al. Lymph node isolated tumor cells and micrometastases in pathological stage I non-small cell lung cancer: prognostic significance. Eur J Cardiothorac Surg 2007;32:863-7.

39. Dai C, Xie H, Kadeer X, et al. Relationship of lymph node micrometastasis and micropapillary component and their joint influence on prognosis of patients with stage I lung adenocarcinoma. Am J Surg Pathol 2017;41:1212-20.

40. Wu J, Ohta Y, Minato H, et al. Nodal occult metastasis in patients with peripheral lung adenocarcinoma of 2.0 cm or less in diameter. Ann Thorac Surg 2001;71:1772-7; discussion 1777-8.

41. Detterbeck FC, Jantz MA, Wallace M, et al. Invasive mediastinal staging of lung cancer: ACCP evidencebased clinical practice guidelines ( 2 nd edition). Chest 2007;132:202S-20S.

42. Nath SK, Sandhu AP, Kim D, et al. Locoregional and 
distant failure following image-guided stereotactic body radiation for early-stage primary lung cancer. Radiother Oncol 2011;99:12-7.

43. Detterbeck FC, Boffa DJ, Kim AW, et al. The eighth edition lung cancer stage classification. Chest

Cite this article as: Biswas A, Jantz MA, Mehta HJ. Pretreatment identification of micro-metastasis in mediastinal lymph node by endobronchial ultrasound-guided transbronchial needle aspiration for early-stage non-small cell lung canceris it time yet? J Thorac Dis 2019;11(10):4096-4100. doi: 10.21037/ jtd.2019.09.41
2017;151:193-203.

44. Arndt AT. A little bit of cancer is still cancer: is it time for lymph node micrometastases in non-small cell lung cancer to get their due? Ann Surg Oncol 2018;25:3781-2. 